\title{
Primary meningitis caused by Bacteroides fragilis and Fusobacterium necrophorum
}

\author{
A. K. M. S. ISLAM* \\ M.B., Dip.Bact., M.R.C.Path. \\ J. M. SHNEERSON†
D.M., M.R.C.P.
}

Departments of Microbiology,* and Medicine, $\dagger$ Whipps Cross Hospital, London E11 1NR

\begin{abstract}
Summary
A fatal case of meningitis due to Bacteroides fragilis and Fusobacterium necrophorum is reported. This appears to be the first case in which meningitis due to these organisms was not secondary to a disease elsewhere in the body. The organisms are difficult to culture and strict anaerobic methods should be used whenever they are suspected. Intravenous metronidazole is probably the antibiotic of choice.

\section{Introduction}

Meningitis due to anaerobic bacteria is rare and is usually secondary to an adjacent septic lesion, particularly otitis media, or to a distant site of infection causing bacteraemia. The authors report a case of Bacteroides fragilis and Fusobacterium necrophorum meningitis which occurred as a primary illness in an otherwise healthy adolescent.
\end{abstract}

\section{Case report}

A previously well 13-year-old girl of West Indian parents was admitted to Whipps Cross Hospital with a 3-day history of headache, vomiting and fever. She had had no significant previous illnesses. On examination she was drowsy and restless, with a temperature of $40^{\circ} \mathrm{C}$. She had severe neck rigidity, positive Kernig's sign and she developed fixed dilated pupils and a right sixth nerve palsy. She had $19 \cdot 7 \times$ $10^{9} / 1$ leucocytes ( $94 \%$ neutrophils) in her peripheral blood.

The cerebrospinal fluid (CSF) pressure was $260 \mathrm{mmH}_{2} \mathrm{O}$. The protein concentration was 0.9 $\mathrm{g} / \mathrm{l}$, glucose $6.1 \mathrm{mmol} / \mathrm{l}$ (simultaneous plasma glucose $12.4 \mathrm{mmol} / \mathrm{l})$, and there were $160 \times 10^{6} / 1$ leucocytes (95\% polymorphs). Gram stains showed a few Gramnegative bacilli, but culture was negative after 6 days aerobic and anaerobic incubation. Blood cultures were also sterile.

She was treated with benzyl penicillin $2.5 \mathrm{Mu}$. and ampicillin $2 \mathrm{~g}$ i.v. 4-hourly, as well as mannitol and

\footnotetext{
Correspondence: A. K. M. S. Islam, Dept. of Microbiology,
} Whipps Cross Hospital, London E11 1NR. dexamethasone. Her condition deteriorated and she became apnoeic. She was intubated and mechanically ventilated but died $24 \mathrm{~h}$ later.

At post-mortem examination, the right cerebral hemisphere was covered with foul-smelling, thick, yellowish pus which was mainly in the subdural space but also in the subarachnoid space (Fig. 1). The right cerebral hemisphere was superficially necrotic and there was an early right occipital abscess which was not apparent macroscopically. There was no evidence of a septic focus elsewhere in the body.

Gram stains of the pus showed scanty Gramnegative bacilli. Culture yielded a heavy growth of $B$. fragilis and $F$. necrophorum after only $48 \mathrm{hr}$ incubation on the pre-reduced anaerobic plates. B. fragilis was sensitive to metronidazole, clindamycin, chloramphenicol and tetracycline but resistant to penicillin, ampicillin and erythromycin. F. necrophorum was sensitive to all the above antibiotics except erythromycin.

\section{Discussion}

Bacteroides and Fusobacterium spp. form part of the commensal flora of the mouth, gut and female genital tract. Bacteroides has been increasingly recognized as a pathogen in wounds and after abdominal surgery where contamination with gut organisms is the probable source of infection (Finegold, 1974; Feathers et al., 1977; Griffiths et al., 1976; Galland et al., 1977). Fusobacterium is occasionally pathogenic in these situations, but its role in causing a wide variety of necrotic lesions (necrobacillosis) in man (e.g. empyema, lung abscess, liver abscess, tubo-ovarian sepsis and septic arthritis) is well recognized (Alston, 1955; Finegold, 1974).

Both organisms are important pathogens in brain abscesses (Owen and Spink, 1948; Markham and Kershaw, 1956; Sanders and Stevenson, 1968; Bartlett, 1974; DeLouvois, Gortvai and Hurley, 1977), and as recently reported, B. fragilis was found in 8 of 9 cases of brain abscess (Ingham, 


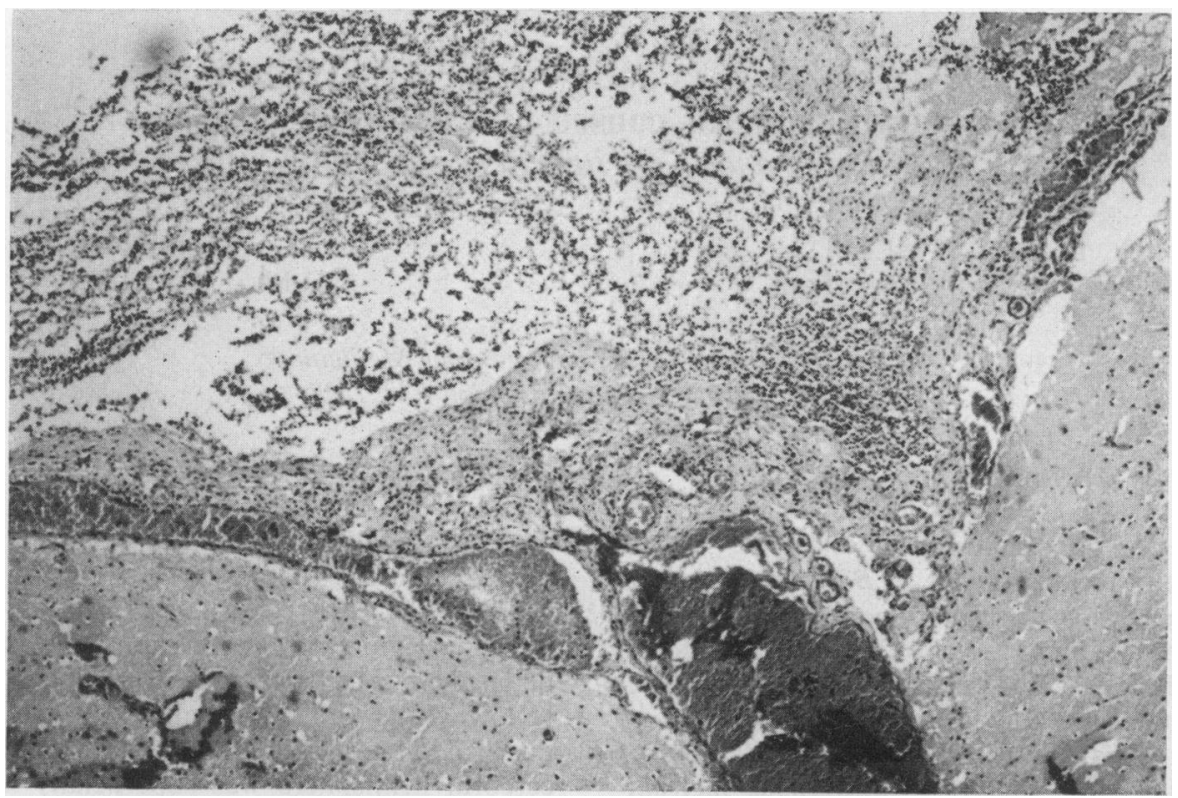

FIG. 1. Brain section showing acute leptomeningitis with extensive subdural exudation $(\mathrm{HE}, \times 90)$.

Selkon and Roxby, 1977). In these series, infection was always associated with an adjacent septic focus, usually otitis media.

Meningitis due to Bacteroides and Fusobacterium is much rarer. It, too, is usually associated with otitis media; but it has also been seen in cases of haematogenous spread from respiratory infections, and following gastrointestinal operations, and in patients with cancer and bacteraemia (Lifshitz, Liu and Thurn, 1963; Cooke, 1975; O'Grady and Ralph, 1976; Feldman, 1976). Bacteroides meningitis has also occurred in one neonate with no source of infection but for whom the membranes had been artificially ruptured before delivery (Dysart et al., 1976).

The present case is unique in that the meningitis occurred despite no septic focus, bacteraemia, operation or evidence of immunosuppression. The organisms may have gained access via the cribriform plate from the naso-pharynx. The predominantly subdural site of infection is interesting and unusual. It is likely that the pia arachnoid (leptomeninges) was the primary site of infection with subsequent extension of infection mainly to the subdural site (Fig. 1). It is avascular, and this probably favours the growth of these obligate anaerobes. Both organisms are pathogenic by themselves, in the presence of coliforms, or in combination with facultative/obligate anaerobic Gram-positive organisms, such as Streptococcus milleri. It is possible that together they exerted a synergistic effect agaia the host defences or, conversely, that they both invaded the same tissues because the local condition were favourable.

Both organisms are difficult to culture and strich anaerobic methods, using pre-reduced blood agaro plates and thioglycollate broth, are necessary. If an initial CSF specimen shows organisms on direce film but a culture yields no growth or negative bacteriology findings in a patient (with an adjacen septic focus, particularly otitis media) who clinically: probably has bacterial meningitis, a second specimen should be obtained for strict anaerobic culture. An early diagnosis of this case of anaerobic meningitis could have been made by using direct gas-liquid chromatography of CSF after suitable extraction procedures (Philips, Tearle and Willis, 1976).

The patient was treated with penicillin and ampicillin in high dosage since the findings of Gram-negative bacilli on direct film suggested the presence of a Haemophilus sp., and in the absences of any predisposing condition anaerobic infection was not suspected; in retrospect, it is felt thatN chloramphenicol instead of ampicillin would have been a better choice. However, Bacteroides and Fusobacterium infections of meninges and braine respond better to metronidazole than to penicillin, clindamycin, lincomycin or choramphenicol (Feld man, 1976; O'Grady and Ralph, 1976), as metronidazole crosses the blood/brain barrier better, and 
CSF/pus levels above the minimal bactericidal concentrations are readily achieved (Feldman, 1976; Ingham et al., 1977). Intravenous metronidazole should be considered where lumbar puncture shows Gram-negative organisms that have failed to grow on culture or when the features of bacterial meningitis are present in a case with an adjacent septic focus, particularly otitis media.

\section{Acknowledgments}

We would like to thank Dr R. S. Winwood for permission to report this patient who was under his care and Dr M. D. E. Evans for her post-mortem report.

\section{References}

Alston, J.M. (1955) Necrobacillosis in Great Britain. British Medical Journal, 2, 1524.

Bartlett, J.G. (1974) Infection with Non-Sporing Anaerobic Bacteria (Ed. by Phillips, I. \& Sussman, M.), p. 131 . Churchill Livingstone, Edinburgh.

Cooke, R.W.I. (1975) Bacteroides fragilis septicaemia and meningitis in early infancy. Archives of Disease in Childhood, 50, 241.

Delouvois, J., Gortvai, P. \& Hurley, R. (1977) Bacteriology of abscesses of the central nervous system: a multicentre prospective study. British Medical Journal, 2, 981.

Dysart Jr, N.K., Griswold, W.R., Schanberger, J.E., Goscienski, P.J. \& Chow, A.W. (1976) Meningitis due to Bacteroides fragilis in a newborn infant. Journal of Pediatrics, 89, 501.

Feathers, R.S., Lewis, A.A.M., SAgor, G.R., Amirak, I.D. \& Noone, P. (1977) Prophylactic systemic antibiotics in colorectal surgery. Lancet, ii, 4.
Feldman, W.E. (1976) Bacteroides fragilis ventriculitis and meningitis. American Journal of Diseases of Children, 130, 880.

Finegold, S.M. (1974) Infection with Non-Sporing Anaerobic Bacteria (Ed. by Phillips, I. \& Sussman, M.), p. 160. Churchill Livingstone, Edinburgh.

Galland, R.B., Saunders, J.H., Mosley, J.G. \& Darrell, J.H. (1977) Prevention of wound infection in abdominal operations by pre-operative antibiotics or povidone iodine. Lancet, ii, 1043.

Griffiths, D.A., Shorey, B.A., Simpson, R.A., Speller, D.C.E. \& Williams, N.B. (1976) Single-dose pre-operative antibiotic prophylaxis in gastro-intestinal surgery. Lancet, ii, 325.

Ingham, H.R., Selkon, J.B. \& Roxby, C.M. (1977) Bacteriological study of otogenic cerebral abscesses, chemotherapeutic role of metronidazole. British Medical Journal, 2, 991.

Lifshitz, F., LiU, C. \& ThURN, A.N. (1963) Bacteroides meningitis. American Journal of Diseases of Children, 105, 487.

MARKhAM, N.P. \& Kershaw, C. (1956) Bacteroides infection. New Zealand Medical Journal, 55, 293.

O'Grady, L.R. \& RalPH, E.D. (1976) Anaerobic meningitis and bacteremia caused by Fusobacterium species. American Journal of Diseases of Children, 130, 871.

OWEN, G.D. \& SPINK, M.S. (1948) Necrobacillosis. Lancet, i, 402.

Philips, K.D., Tearle, P.V. \& Willis, A.T. (1976) Rapid diagnosis of anaerobic infection by gas-liquid chromatography of clinical material. Journal of Clinical Pathology, 29, 428.

Sanders, D.Y. \& Stevenson, J. (1968) Bacteroides infections in children. Journal of Pediatrics, 72, 673. 